\title{
Bony Landmarks as an Aid for Intraoperative Facial Nerve Identification
}

\author{
L.M. Greyling, ${ }^{1}$ R. Glanvill, ${ }^{1}$ J.M. Boon, ${ }^{+1}$ D. Schabort, ${ }^{1}$ J.H. Meiring, ${ }^{1}$ J.P. Pretorius, ${ }^{2}$ And A. Van Schoor ${ }^{1}$

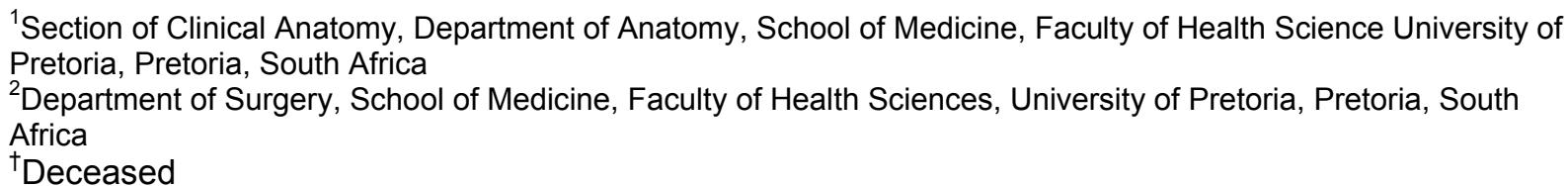

Identification of the facial nerve trunk is essential during surgery of the parotid gland. Numerous landmarks have been researched and used. The relation between the facial nerve to two constant bony landmarks, the tip of the mastoid process and the central point of the transverse process of the atlas was investigated. Forty cadavers were dissected. A preauricular incision exposed the nerve trunk. Bony landmarks were identified and marked. The distance from the nerve trunk to the mastoid process and the atlas was measured. The mean distance between the mastoid process and nerve for the left was $9.18 \pm 2.05 \mathrm{~mm}$ and for the right, $9.35 \pm 1.67 \mathrm{~mm}$. The mean distance between the atlas and the nerve for the left was $14.31 \pm 3.59 \mathrm{~mm}$ and for the right, $13.76 \pm 4.65 \mathrm{~mm}$. Confidence intervals were determined. The importance of the aforementioned data revolves around minimizing the chance of injury to the facial nerve during surgery. The applicability of these landmarks needs to be studied in the clinical setting.

\section{Introduction}

The parotid gland, the largest salivary gland, occupies an irregular area between the ear and ramus of the mandible. The facial nerve exits through the stylomastoid foramen and enters the parotid gland where it divides into the cervicofacial and temporofacial divisions, which then further divide into five peripheral branches to supply the muscles of facial expression (Meiring et al., 1996). Embryologically, the parotid gland developed in the so-called crotch of the facial nerve where the main stem divides into its major temporofacial and cervicofacial divisions. As the gland develops it surrounds the facial nerve and its branches. The facial nerve and its branches always lie in one plane, thereby dividing the parotid gland into a deep and superficial lobe. There is no anatomical plane between the lobes (Heeneman, 1975).

It is of utmost importance that the facial nerve is identified and exposed prior to removal of parotid tumors (Heeneman, 1975). Facial nerve paralysis is a devastating complication of parotid surgery (Witt, 1998). It is, thus, essential that the concept of facial nerve identification be incorporated in the technique of parotid gland surgery (Conley, 1978). Therefore, localization and preservation of the facial nerve should precede the removal of a diseased gland unless the nerve is to be sacrificed because of invasion by a tumor (Keyes and Tenta, 1985). The incidence of permanent facial nerve paralysis or paresis after benign tumor surgery is between $3 \%$ and $5 \%$ and that of postoperative transient facial nerve dysfunction, between $8.2 \%$ and $65 \%$ (Witt, 1998). During parotid gland surgery, preservation of the facial nerve depends upon its proper exposure by means of meticulous dissection (de Ru et al.2001) 
Exposure of the main trunk of the facial nerve at its origin was first described in 1940, and it was stated that, "it enables one to determine without cutting into the tumor exactly how much of the nerve must be sacrificed to permit satisfactory ablation of malignant growth" (Heeneman, 1975).

Roscic (1980) introduced the preauricular incision as a new surgical technique, explaining that the main advantage of this technique is, because of the remarkable consistency of the position of the nerve trunk, that it offers the opportunity to locate the nerve in the retromandibular fossa. Many new approaches have since been developed. From descriptions of these and other landmarks used to identify the main stem of the facial nerve, one could deduce that no conclusive evidence exists that any one landmark is reliable to identify the facial nerve. Identification of the nerve trunk with the aid of the following landmarks have been studied, namely, the origin of the posterior belly of digastric, the styloid process, the mastoid process, the tympanomastoid fissure, the tragal cartilage, and the bony ridge at the anteroinferior margin of the external auditory meatus (Maran, 1973; Heeneman, 1975; Roscic, 1980; Keyes and Tenta, 1985; de Ru et al., 2001; Salame et al., 2002).

The reliability of soft tissue landmarks varies. It is known that the anatomy of soft tissue structures could be distorted in infants, children, previous surgical intervention, intensive scarring and the extent of the tumor itself, and creates exceptionally difficult problems in the execution of basic surgical techniques (Conley, 1978). Both the length and curvature of the styloid process are variable; thus rendering it an equally unreliable landmark (Williams et al., 1995). Other criticisms concerning one method or another include no sense of depth, unreliable measurements, and variability from retraction, danger from being too deep or necessity for additional dissection (Wong, 2001).

\begin{abstract}
Aims
Bony structures are more suitable as anatomical guides because of their rigid and reliable anatomical location (de Ru et al., 2001). This study aimed to identify the position of the facial nerve and its relationship to two easily palpable and constant bony landmarks, namely, the most inferior tip of the mastoid process and the most central point on the transverse process of the atlas (C1).
\end{abstract}

\title{
Materials and Methods
}

A total of 40 embalmed facial halves (20 left and 20 right) were dissected and studied. Cadaver material was obtained from the Department of Anatomy at the University of Pretoria under the Human Tissues Act 65 of 1983 of South Africa. No ethical clearance was needed. The heads were turned to the lateral side to expose the preauricular region for dissection, similar to the positioning during surgery. A preauricular incision that extends from 10-mm superior to the tragal cartilage to a point $20-\mathrm{mm}$ inferior to the angle of the mandible was made (Roscic, 1980).

The skin flaps were elevated and tucked away to prevent obscured vision, and subcutaneous tissue dissected away. The main trunk of the facial nerve was exposed without displacing the 
course or position of the nerve. The next step was to identify the bony landmarks and clear them of any soft tissue. The landmarks were then marked by means of pins. The specific points on the landmarks that were used were the most inferior tip of the mastoid process and the most central point on the transverse process of the atlas (C1). This specific location is necessary as both these landmarks and especially the mastoid process is a bulky landmark and therefore the reference point on this landmark was specifically defined. The shortest distance from the nerve trunk to the tip of the mastoid process ( $\alpha$ ) (Fig. 1), and to the most central point of the transverse process ( $\beta$ ) (Fig. 2) was measured on both sides. Two independent observers took measurements by means of a digital caliper (accuracy: $0.1 \mathrm{~mm}$ ). The mean of the two measurements was used.

Statistical analysis was performed to determine differences in measurements between sexes, sides, weight, and length by means of a general ANOVA. Statistix ${ }^{\circledR}$ version 8 analytical software was used for statistical analysis. Linear regression was performed to determine the association between the length of the cadaver and each of the measurements from the nerve trunk to the tip of the mastoid process $(\alpha)$ and the most central point of the transverse process $(\beta)$ respectively, for males and females. Prediction values for these measurements on the basis of height, varying from 1.20 to $1.80 \mathrm{~m}$ (range of the female sample size) and from 1.50 to $1.90 \mathrm{~m}$ (range of the male sample size), were calculated and illustrated by means of scatter plots (Figs. 3a-3d).

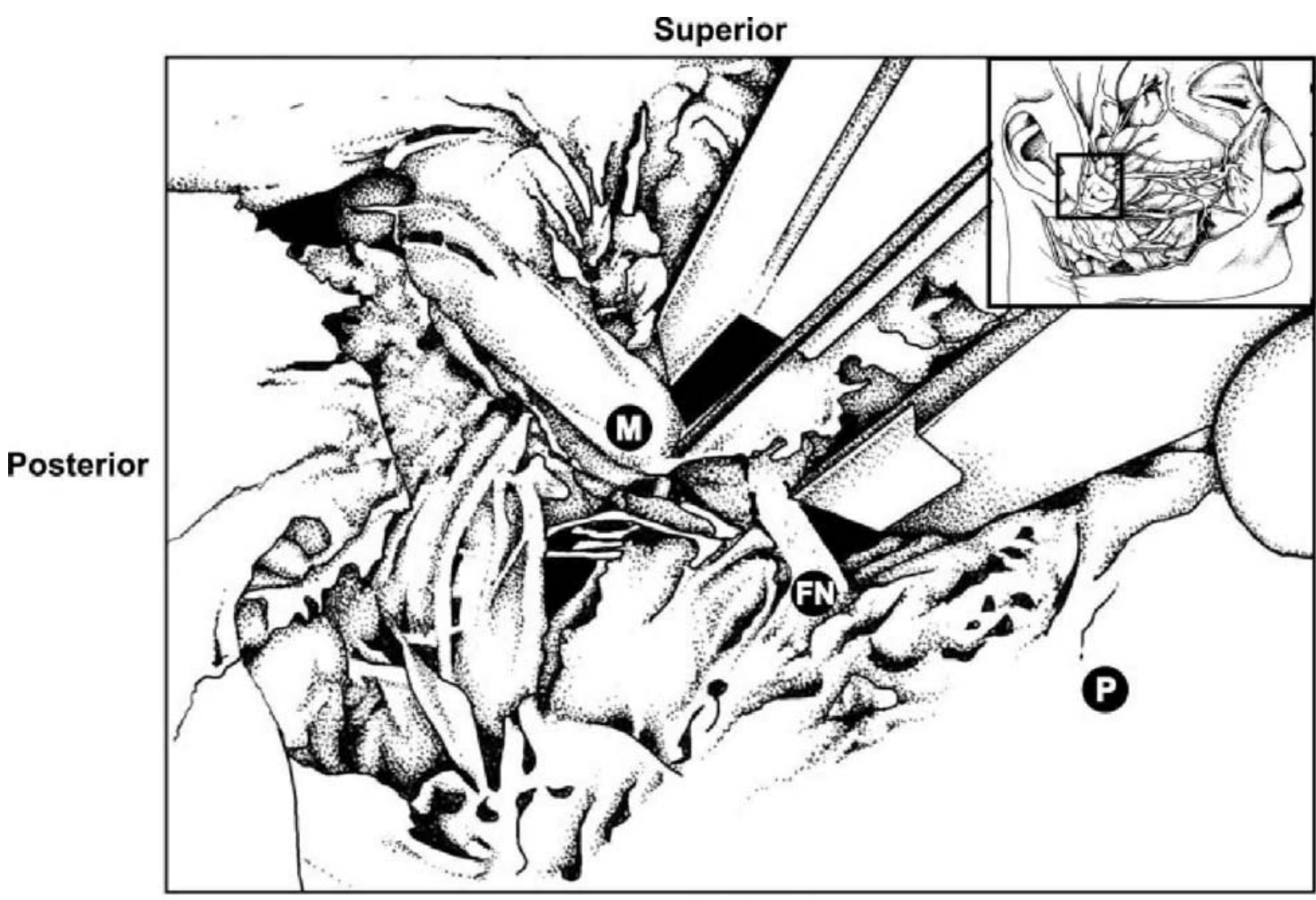

Anterior

Inferior

Fig. 1. Distance between the mastoid process to main trunk of the facial nerve. M, mastoid process; FN, Main trunk of facial nerve. 


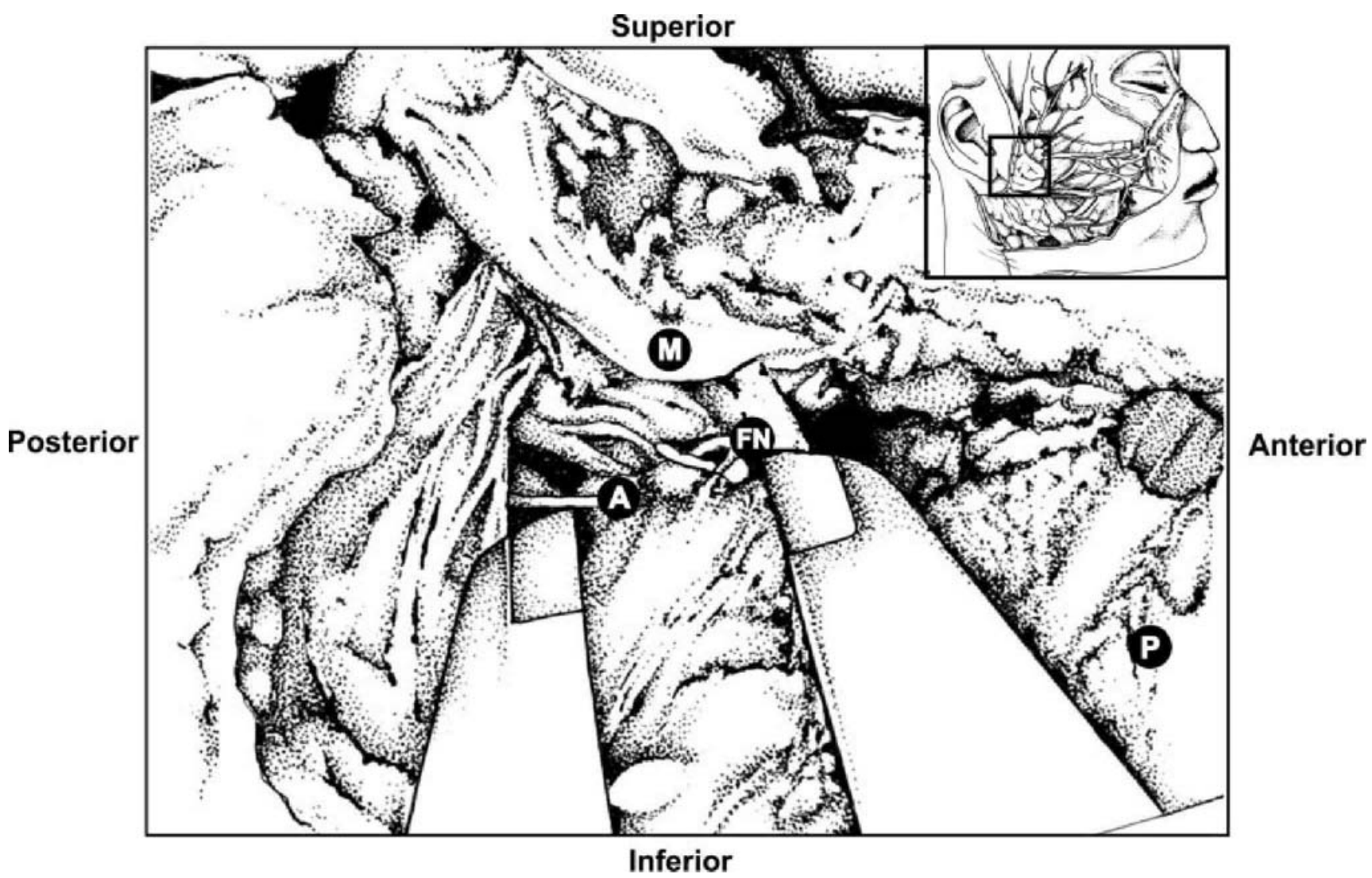

Fig. 2. Distance between the transverse process of $\mathrm{C} 1$ to the main trunk of the facial nerve. $\mathrm{M}$, mastoid process; A, transverse process of atlas; FN, Main stem of facial nerve.

\section{Results}

The demographic profile of the cadaver population that was used ( $n=40$ facial halves) was as follows:

Age (years): range $30-98$, mean: 67.76 , median: 71.50

Height $(\mathrm{cm})$ : range 127-183, mean: 165, median: 166

Weight (kg): range $26.70-75.30$, mean: 50.28 , median: 50.60

Sex: male 26, female 14.

The measurements (Table 1) revealed a mean distance from the inferior tip of the mastoid process to the facial nerve trunk on the right as $9.35 \mathrm{~mm}$ (SD: $1.67 \mathrm{~mm}$ ) and on the left as $9.18 \mathrm{~mm}$ (SD: $2.05 \mathrm{~mm}$ ). The mean distance from the most central point on the transverse process of the atlas $(\mathrm{C} 1)$ to the facial nerve trunk on the right was $13.76 \mathrm{~mm}$ (SD: $4.65 \mathrm{~mm}$ ) and on the left, $14.31 \mathrm{~mm}$ (SD: $3.59 \mathrm{~mm}$ ). It is evident form the earlier that there is a small degree of variation between left and right halves; however, no significant differences were noted. A summary of the data is presented in Table 1. 
TABLE 1. The Mean, Standard Deviation (SD), Median, 5th and 95th Percentile (in $\mathrm{mm}$ ) of the Right and Left Sides of the Measurements Taken from the Tip of the Mastoid Process and the Most Central Point of the Transverse Process of the Atlas to the Facial Nerve Respectively

\begin{tabular}{|c|c|c|c|c|}
\hline & $\begin{array}{c}\text { Mastoid process } \\
\text { to nerve } \\
\text { (right) }\end{array}$ & $\begin{array}{c}\text { Mastoid process } \\
\text { to nerve } \\
\text { (left) }\end{array}$ & $\begin{array}{c}\text { Transverse } \\
\text { process C1 to } \\
\text { nerve (right) }\end{array}$ & $\begin{array}{c}\text { Transverse } \\
\text { process C1 to } \\
\text { nerve (left) }\end{array}$ \\
\hline Mean & 9.35 & 9.18 & 13.76 & 14.31 \\
\hline SD & 1.67 & 2.05 & 4.65 & 3.59 \\
\hline Median & 9.14 & 8.51 & 13.74 & 14.14 \\
\hline $5^{\text {th }}$ percentile & 7.58 & 6.69 & 6.99 & 9.04 \\
\hline 95th percentile & 11.25 & 12.76 & 21.71 & 18.97 \\
\hline
\end{tabular}

When considering $90 \%$ sample coverage, the facial nerve is found $7.58-11.25 \mathrm{~mm}$ from the inferior tip of the mastoid process on the right and 6.69-12.76 $\mathrm{mm}$ on the left (5th to 95th percentile); and 6.99-21.71 $\mathrm{mm}$ from the most central point of the transverse process of the atlas (C1) on the right and $9.04-18.97 \mathrm{~mm}$ on the left (Table 1).

Analysis indicated no significant difference in measurements irrespective of weight, length, sex, and side. A regression equation for the facial nerve to the inferior tip of the mastoid process for females was calculated as $\alpha(\mathrm{mm})=2.60+(3.86 \mathrm{x}$ height $)$, and for facial nerve to the most central point of the transverse process as $\beta(\mathrm{mm})=23-(6.20 \times$ height); where height represents the patient's height ( $\mathrm{m})$ (Figs. 3a and 3b).

The regression equation for the facial nerve to the inferior tip of the mastoid process for males was calculated as $\alpha(\mathrm{mm})=10-(0.72 \times$ height $)$, and for facial nerve to the most central point of the transverse process as $\beta(\mathrm{mm})=9.66-(2.83 \times$ height $)$; where height represents the patient's height $(\mathrm{m})$ (Fig. 3c and 3d). 


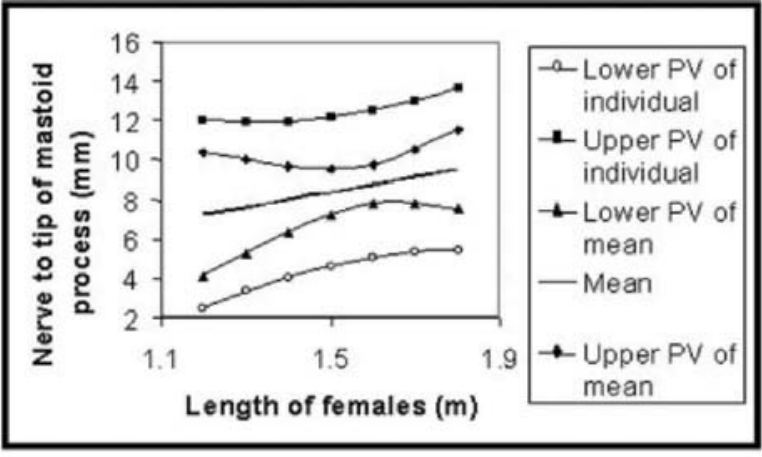

a

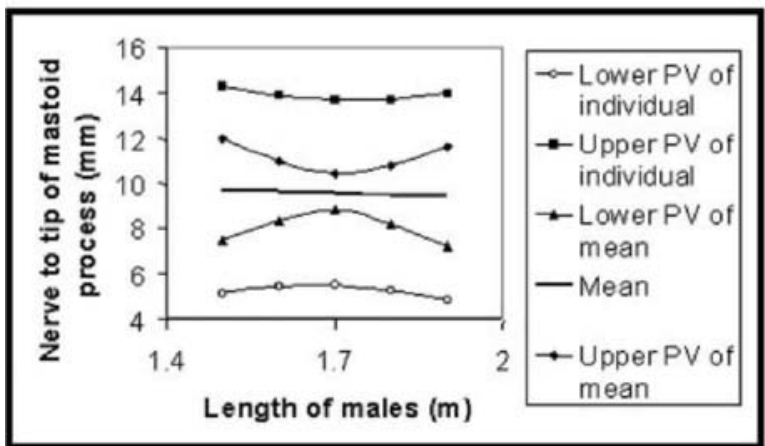

C

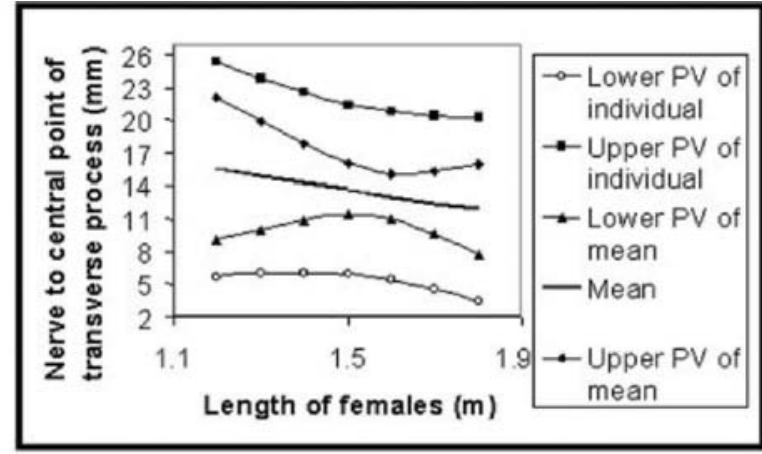

b

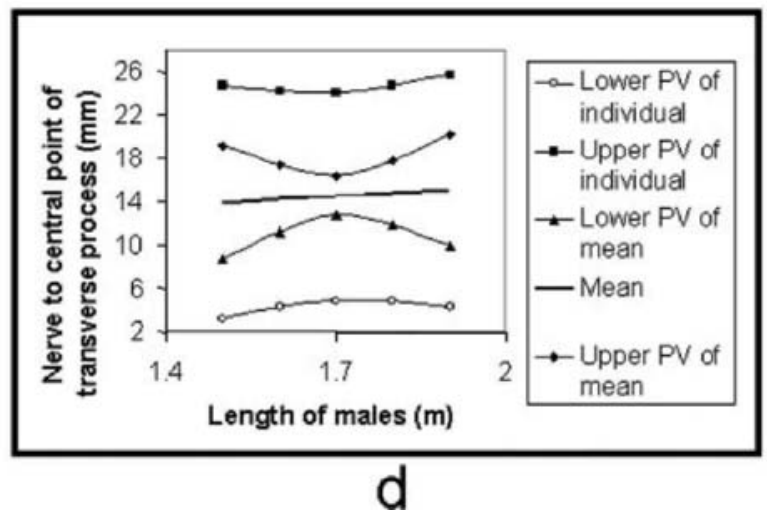

Fig. 3. Scatter plot of a: measurement $\mathbf{a}(\mathrm{mm})$ to the length of the female cadaver/patient $(\mathrm{m})$ illustrating the regression equation of $\alpha(\mathrm{mm})=2.60+(3.86 \times$ length $)$. ( $P V=$ Prediction Values $)$.

b: Measurement $\beta(\mathrm{mm})$ to the length of the female cadaver/patient $(\mathrm{m})$ illustrating the regression equation of $\beta$ $(\mathrm{mm})=23-(6.20 \times$ length $)$.

c: Measurement $\alpha(\mathrm{mm})$ to the length of the male cadaver/patient $(\mathrm{m})$ illustrating the regression equation of $\alpha$ $(\mathrm{mm})=10-(0.72 \times$ length $)$.

d: Measurement $\beta(\mathrm{mm})$ to the length of the male cadaver/patient $(\mathrm{m})$ illustrating the regression equation of $\beta$ $(\mathrm{mm})=9.66-(2.83 \times$ length $)$.

\section{Discussion}

Landmarks for facial nerve trunk identification was described in the earlier part of the previous century as a result of the general awareness of poor surgical results (Wong, 2001). Landmarks selected must be reliable and, above all, easy to identify (Roscic, 1980). Bony structures are more suitable than soft tissue or cartilaginous landmarks because of their rigid and reliable anatomical location (de Ru et al., 2001). One of the problems, though, is that palpation of certain bony landmarks could be difficult.

Maran (1973) described his method in which the tail of the parotid gland is dissected away from sternocleidomastoid and moved posterior, and the posterior belly of digastric is identified and followed up to its insertion on the mastoid process. An angle is formed where the muscle crosses the tympanic plate of the petrous bone and bisecting this angle is the facial nerve. In other studies, three different methods of facial nerve identification were used namely, identifying the posterior belly of digastric and the mastoid process, finding the tympanomastoid suture in the space between the external acoustic meatus and the mastoid process, the so-called "valley" for the nerve, and thirdly, exposing the facial nerve trunk on 
entering the parotid gland, then following the styloid process up to the stylomastoid foramen and identifying the nerve upon exiting the stylomastoid foramen. In this instance, the styloid process was seen to be consistent with the facial nerve trunk that passes laterally and inferiorly in an oblique direction near its root. The second step, involving the "valley" of the nerve (retromandibular fossa), was stated as being the safest and most reliable of the three methods of identification (Heeneman, 1975; Conley, 1978). Salame et al. (2002) determined the distance between the facial nerve trunk at the stylomastoid foramen and the tip of the mastoid process, and found it to be $17.22 \pm 3.18 \mathrm{~mm}$. The depth from the mastoid tip to the facial nerve trunk at the stylomastoid foramen has been estimated at $2 \mathrm{~cm}$.

In his article, Maran (1973), eluded upon some problems experienced with the styloid process and found that the styloid process was difficult, or even impossible, to palpate. He also reported that the styloid process was an unreliable landmark as a result of its absence in $30 \%$ of his 350-cadaver sample. Thus, although there is a distinct possibility that bony landmarks are not always constant or present, they still prove to be more reliable than soft tissue structures (Maran, 1973).

Some authors regard the tympanomastoid fissure as the most reliable landmark (Heeneman, 1975; Keyes and Tenta, 1985; de Ru et al., 2001). It is identified as the landmark closest to the main trunk of the facial nerve (de Ru et al., 2001). It is stated as being easily identifiable, its position is constant, and its relation to the facial nerve is reliable and allows for the nerve to be identified close to the foramen where it is least subject to displacement (Heeneman, 1975). The results of several studies showed that the nerve lies within $6-8 \mathrm{~mm}$, or $0.5-1 \mathrm{~mm}$, or $3 \mathrm{~mm}$ medial to, or deep to the end of the tympanomastoid fissure (Heeneman, 1975; Conley, 1978; Keyes and Tenta, 1985; de Ru et al., 2001). Even though Ear, Nose, and Throat surgeons regard it as the most useful landmark, it is often difficult to find the right drop-off point of the suture (de Ru et al., 2001).

Another landmark considered as stable is the lowermost medial projection of the tragal "pointer" or cartilage, which lies anterior to the opening of the external acoustic meatus (Heeneman, 1975). This "pointer" points directly to the facial nerve upon exiting the stylomastoid foramen (Maran, 1973; Heeneman, 1975). The facial nerve exits $\sim 1 \mathrm{~cm}$ below and medial to the tip of the tragal "pointer" (Maran, 1973). One problem with using the tragal "pointer" is that various observers interpret the definition and direction of the "pointer" differently. Difficulty to decide on the position of the tragal "pointer" exists because it is mobile, asymmetrical and has a blunt irregular tip (de Ru et al., 2001).

The present study focused on determining landmarks that were always present, constant and palpable and in close proximity to the nerve trunk. The mastoid process has been studied in previous literature but no mention has been made regarding the vertebrae and in particular the atlas $(\mathrm{C} 1)$, which lies in very close proximity to the nerve. The lateral process of $\mathrm{C} 1$ is easily palpated in the angle formed by the posterior belly of digastric and stylohyoid and the terminal portion of the external carotid artery, and, immediately lateral to it, the internal jugular vein (Keyes and Tenta, 1985). There have been no reported cases of either of these bony landmarks being absent and their positions afford them to easy nerve identification. Thus, this study proposes one new landmark namely; the most central point on the transverse process of $\mathrm{C} 1$, which during the study seemed to be valuable in facial nerve identification. 
By using the height of the male or female cadaver, or patient, the regression equations could be used to determine the distances ( $\alpha$ and $\beta$ ) from the facial nerve trunk to the bony landmarks. For example the measurement $\alpha$ (from the facial nerve trunk to the tip of the mastoid) for a female with a height of $1.30 \mathrm{~m}$ :

$$
\begin{aligned}
\alpha(\mathrm{mm}) & =2: 60+(3: 86 \times \text { height }) \\
& =2: 60+(3: 86 \times 1: 30) \\
& =7: 62 \mathrm{~mm}
\end{aligned}
$$

Limitations of the study include the following: The sample size can be regarded as small and a larger sample may provide a greater degree of variation between left and right halves. Another may be the fact that the sample was not evenly distributed between Caucasoid and Negroid and both genders. These factors may have an effect on the position of the facial nerve trunk. Nerve position alterations during the subsequent dissection may have played a role in the results but extreme caution was taken to ensure minimal nerve movement from its normal position. Another factor to take into account was that embalmed cadaver material was used and the sample population therefore fixed. The body was fixed in the neutral anatomical position with the neck semi-extended and turned laterally, similar to surgical procedures in the parotid region, for access to the facial nerve trunk. There may however be variations in the distances from the landmarks to the nerve trunk in a living person and people with varying body compositions (endo-, meso-, and ectomorph). These factors were all unaccounted for in this study.

\section{Conclusion}

The region of safety described in the results offers surgeons information pertaining to the landmarks and the distance from them where facial nerve injury may result. Thus, in conclusion, the use of the aforementioned stable landmarks and regression equations may decrease the risk of facial nerve injury during parotid region surgery. It is of utmost importance that it is kept in mind that this study was performed on fixed cadaver material and follow up results need to be attained in vivo by performing the techniques clinically.

\section{References:}

Conley J. 1978. Search for and identification of the facial nerve. Laryngoscope 88:172-175.

de Ru JA, van Benthem PP, Bleys RL, Lubsen H, Hordijk GJ. 2001. Landmarks for parotid gland surgery. J Laryngol Otol 115:122- 125.

Heeneman H. 1975. Identification of the facial nerve in parotid surgery. Can J Otolaryngol 4:145-151.

Keyes GR, Tenta LT. 1985. Surgery of the parotid gland and the viscerovertebral angle.lin Plast Surg 12:323-330. 
Maran AG. 1973. Identification of the facial nerve in parotid surgery. J R Coll Surg Edinb 18:58-59. Meiring JH, Liebenberg SW, van Heerden L, Jacobs CJ, Vorster W, Scheepers MD, Greyling LM. 1996. Human Anatomy. Pretoria: Van Schaiks. p 220-222.

Roscic Z. 1980. Conservative parotidectomy: A new surgical concept. J Maxillofac Surg 8:234-240.

Salame K, Ouaknine GE, Arensburg B, Rochkind S. 2002. Microsurgical anatomy of the

Meiring JH, Liebenberg SW, van Heerden L, Jacobs CJ, Vorster W, Scheepers MD, Greyling LM. 1996. Human Anatomy. Pretoria: Van Schaiks. p 220-222.

Roscic Z. 1980. Conservative parotidectomy: A new surgical concept. J Maxillofac Surg 8:234-240.

Salame K, Ouaknine GE, Arensburg B, Rochkind S. 2002. Microsurgical anatomy of the facial nerve trunk. Clin Anat 15:93-99.

Williams PL, Bannister LH, Berry P, Collins MM, Dyson M, Dussek JE, Ferguson MWJ. 1995. Styloid Process. In: Williams PL, Bannister LH, Berry P, Collins MM, Dyson M, Dussek JE, Ferguson MWJ, editors. Gray's Anatomy. 38th Ed. New York: Churchill Livingstone. p 561, 592.

Witt RL. 1998. Facial nerve monitoring in parotid surgery: The standard of care? Otolaryngol Head Neck Surg 119:468-470.

Wong DS. 2001. Surface landmarks of the facial nerve trunk: A prospective measurement study. ANZ J Surg 71:75 